\title{
A Study on the Influence of Hot Press Forming Process Parameters on Flexural Property of Glass/PP Based Thermoplastic Composites Using Box-Behnken Experimental Design
}

\author{
B. Senthil Kumar ${ }^{1}$ and Subramanian Balachandar ${ }^{2}$ \\ ${ }^{1}$ Department of Rural Industries and Management, Gandhigram Rural Institute, Deemed University, Gandhigram 624302, India \\ ${ }^{2}$ PACR Polytechnic, Rajapalayam, India \\ Correspondence should be addressed to B. Senthil Kumar; senthil.b1980@gmail.com
}

Received 14 November 2013; Accepted 29 December 2013; Published 4 March 2014

Academic Editors: K. Hokamoto, J. Rubio, V. Sglavo, and N. Uekawa

Copyright (C) 2014 B. S. Kumar and S. Balachandar. This is an open access article distributed under the Creative Commons Attribution License, which permits unrestricted use, distribution, and reproduction in any medium, provided the original work is properly cited.

\begin{abstract}
A thermoplastic composite is produced from polypropylene matrix with glass fibre reinforcement. These types of composite materials are ecofriendly nature due to their reusability after their lifetime. These polymer composites are alternative to heavy metals that are currently being used in many non-structural applications. In spite of being ecofriendly nature, the range of applications is limited due to poor mechanical properties as compared with thermoset matrix composite. Hence an attempt was made in this work to improve the mechanical property such as flexural property of Glass/PP hybrid woven composites by optimizing the parameters during compression moulding, such as mould pressure, mould temperature, and holding time using Box-Behnken experimental design. Each process variables were taken in 3 different levels. Second order polynomial model with quadratic effect was chosen. The optimum combination of process parameters was obtained by using contour diagram. The levels of importance of process parameters on flexural properties were determined by using analysis of variance (ANOVA). The variation of flexural property with cited process parameters was mathematically modelled using the regression analysis.
\end{abstract}

\section{Introduction}

It is a truism that technology development depends on advances in the field of materials. One cannot imagine the most advanced turbine or aircraft design without adequate materials to bear the service loads. The final limitation of any development is limited by the advancement of materials. In this contest nowadays polymeric composite materials are nonignorable. There has been always increasing demand for materials [1] that are stiffer and stronger and lighter which are used in the field of aerospace, energy, and civil constructions. Advanced composite material satisfies the above requirement.

Throughout the prior two decades, fiber reinforced composite materials were principally fabricated using thermosetting matrices $[2,3]$. The important disadvantages stemming from the use of thermosets include brittleness, lengthy cure cycles, and inability to repair and recycle the damaged or scrapped parts. These disadvantages led to the development of the thermoplastic matrix composite system. Compared with thermosets composites, the thermoplastic fibre reinforced composites are having longer shelf life and higher strain to failure and are faster to consolidate and retain the ability to be repaired, reshaped, and reused as need arises. In addition to this, due to the high emphasis on production of eco-friendly products, has also been insisted from all parts of the world [4], the design and development of such kind of reusable thermoplastic fibre reinforced composites are given further importance.

These types of ecofriendly materials find their way in several structural and nonstructural applications where they are not subjected to high loads. Poor wettability, insufficient 

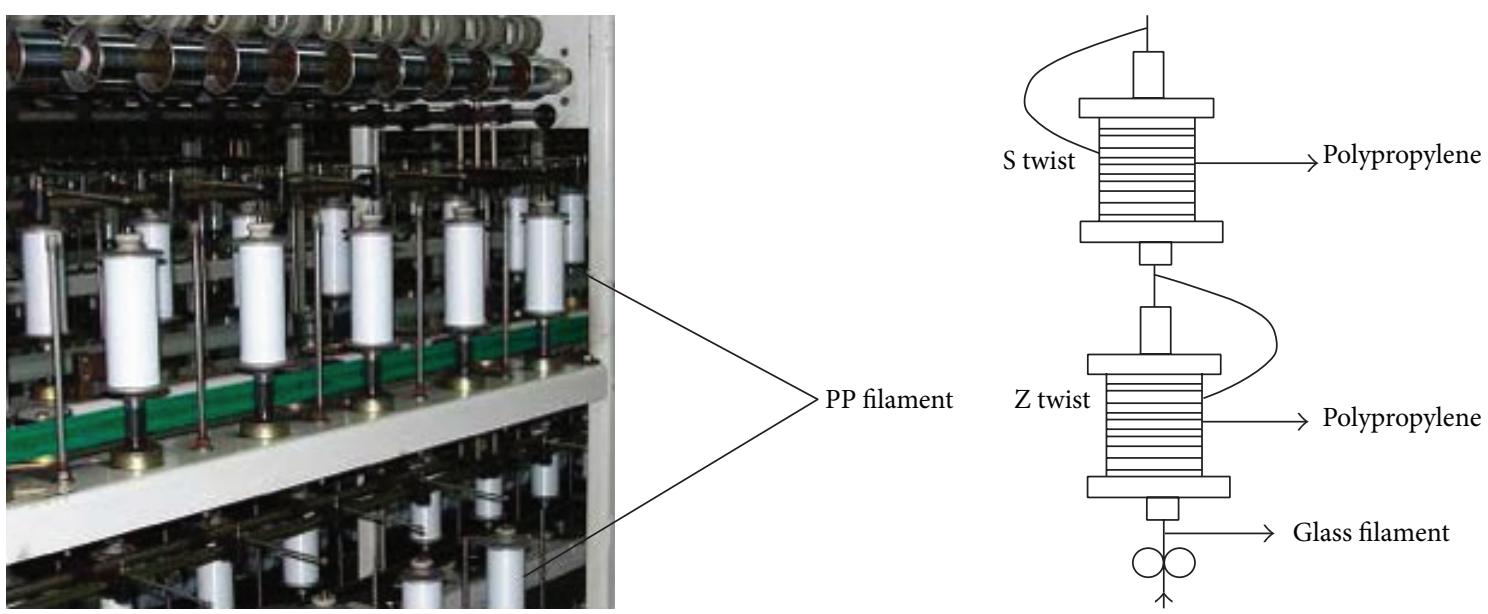

Figure 1: Modified Wrapping machine.

adhesion between fiber and polymer, void formation, and improper processing methods are the key factors that are limiting the applications of these materials. Extensive researches were carried out by various researchers throughout the world on improving the fiber matrix adhesion by various fiber surface treatments [5-8]. Additional problems caused by high matrix viscosity during consolidation include dealignment of reinforcing fibers during consolidation as well as the introduction of voids within the final composite product [9] that creates strength loss of the final material.

Processing parameters during moulding significantly influences the properties and interfacial characteristics of the composites [10]. Therefore, suitable processing parameters must be carefully selected in order to yield the optimum composite products [10]. Most important hot press forming parameters that influence the mechanical properties are temperature, pressure, and heating time. Ochi [11] studied the effect of processing temperature on tensile and flexural strengths of unidirectional kenaf/PLA composites and found the optimum temperature is $1600^{\circ} \mathrm{C}$. Bernard et al. [12] investigated the effect of processing parameters including temperature and speed on mechanical properties of kenaf fiber plastic composites and found a new trend in processing parameters of long kenaf fiber plastic composites. Takagi and Asano [13] studied the effect of processing pressure on the flexural strength and moduli of the green composites. They found an increase in flexural strength and modulus with increasing molding pressure. Rassmann et al. [14] observed an increase in tensile and flexural strength with processing pressure. In addition, cooling system, preheating time, recrystallization and soak time, and so forth will also have an influence on the mechanical properties of the thermoplastic composites [15]. Hence an attempt is made to analyze the impact of hot press forming process parameters on mechanical properties of Glass/PP based thermoplastic composites. For this purpose, an inexpensive and easy to operate experimental strategy based on Box-Behnken design has been adopted to study the effect of various process parameters. This experimental procedure has already been successfully applied for optimization of citric acid production from corn starch using Aspergillus niger [16]. The present study aims at studying the influence of process parameters on flexural properties of Glass/PP fibre based thermoplastic composite using the Box-Behnken method.

\section{Research Procedure}

In this research work preparation of glass wrapped polypropylene hybrid yarn is produced by a modified double yarn wrapping machine. The schematic diagram of the yarn wrapping machine is indicated as in Figure 1. Using this wrapped yarn, plain woven fabric preform has been produced through hand loom with controlled fabric GSM. This woven fabric was made into $12 \times 12 \mathrm{~cm}$ samples; nine such layers of pieces were made into one bunch which is used to produce a composite piece. The fabric layers are placed into the oven for preheating then these preheated samples were transferred to the compression moulding unit for composite production. At the time of moulding the process parameters (mould temperature, mould pressure, and holding time) are studied for optimization. Box-Behnken experimental design was utilized to conduct the experiments.

\section{Experimental Details}

3.1. Materials. Glass filament (610D) and polypropylene fibre (840D) were procured from ACME Fibre Ltd., Chennai, India. According to the ASDM standards the physical properties of these fibres were analysed and the details are given as in Table 1 .

3.2. Wrapped Yarn. The glass and polypropylene yarn were wrapped appropriately with the specially designed filament wrapping machine (as shown in Figure 1) with the form of bicomponent yarn with $40 \%(\mathrm{~W} / \mathrm{W})$ of glass fibre and $60 \%$ (W/W) of polypropylene fibre. The real challenges while making wrapped yarn was due to improper compatibility in elasticity and tensile behaviour of both filaments. Glass filament is having poor elasticity as well as brittle nature, whereas 
TABLE 1: Physical, mechanical, and thermal properties of glass and polypropylene fibres.

\begin{tabular}{lcc}
\hline Fibre types & E-Glass fibre & Polypropylene \\
\hline Fibre denier & $610 \mathrm{D}$ & $840 \mathrm{D}$ \\
Density (g/c.c) & 2.62 & 0.9 \\
Tensile strength (Mpa) & 3400 & 40 \\
Melting point & $>800^{\circ} \mathrm{C}$ & $135^{\circ} \mathrm{C}$ \\
\hline
\end{tabular}

the polypropylene is having good elasticity. So the specially designed wrapping machine is utilized for doubling these yarns together.

This machine contains creel (raw material feeding zone) which has some provision to accommodate the glass filament bobbin. Then a polished guide roller is situated in this machine, which guides the glass filament without much of bending. A hollow spindle of this machine has a provision to accommodate the polypropylene bobbin around it. This polypropylene is wrapped around the glass filament properly by means of the rotation of hollow spindle.

3.3. Plain Woven Structure (Preform). A narrow width (24inch width in size) loom was utilized to produce the woven preform $(1 \times 1$ plain structure), which is the raw material for composite preparation. Both the ends per inch and picks per inch of the proposed fabric are twelve. Polished small size weft package was maintained. Since the glass fibres are possessing poor flexural abrasion properties, polished reed and heald shaft was used for smooth weaving.

3.4. Thermoplastic Composite Processing. A Gen lab $3.5 \mathrm{~kW}$ hot air oven was used for preheating the preform (Glass/PP wrapped-plain-woven plied structure). Fabric samples were cut into $12 \times 12 \mathrm{~cm}$ size. Nine layers of such samples were considered as the final preform. Subsequently, the mild steel mould is fabricated to fit with the hydraulic moulding press. Preheating was done in $5 \mathrm{~min}$ of time intervals. This preheating minimizes the void formation.

3.5. Compression Moulding Equipment. Muller 1250 tone hydraulic press compression moulding machine with closed loop parallelism control was utilized for polymer moulding. A cast iron mould is produced with the dimension of $12 \mathrm{~cm} \times 12 \mathrm{~cm} \times 3 \mathrm{~cm}$, where in the preheated preform was kept. This whole assembly was placed over the working area of the hydraulic press equipment to actuate the compression moulding machine. The moulding process is carried out in a nonisothermal condition. During these trails, the upper bolster closed at velocity of $30 \mathrm{~mm} / \mathrm{min}$. A thermocouple was used to measure the temperature at moulding.

3.6. Flexural Strength. Three point bending tests were conducted using a universal testing machine (INSTRON 3385). Tests were carried out in accordance with ASTM D 790
TABLE 2: Process variables and their actual values for the coded values in the experimental design.

\begin{tabular}{lccc}
\hline Process parameters & \multicolumn{3}{c}{ Levels } \\
& +1 level & 0 level & -1 level \\
\hline (X1) Mould pressure (bar) & 10 & 15 & 20 \\
(X2) Mould temperature $\left({ }^{\circ} \mathrm{C}\right)$ & 200 & 220 & 240 \\
(X3) Holding time (min) & 2 & 3 & 4 \\
\hline
\end{tabular}

with a cross head speed of $2 \mathrm{~mm} / \mathrm{min}$. Flexural strength was determined using the following equation:

$$
\mathrm{Fs}=\frac{3 P L}{2 B t^{2}},
$$

where $P$ is the maximum load, $L$ is the span length, and $B$ and $t$ are width and thickness of the specimen.

\section{Experimental Design}

The design of experiments is a powerful tool for modelling and analyzing the influence of control factors on performance output. Design Expert software has been utilized to perform this task. The most important part of the design of experiments lies in the suitable selection of the control factors. An exhaustive literature review on mechanical properties of fibre reinforced polymer composites reveals that parameters such as mould temperature, mould pressure, and holding time (time at melt recrystallization) largely influence the mechanical properties of polymer composites. The impact of these three parameters is studied using Box-Behnken design. Here, only the main effects and their interactions are analysed in quadratic model. The processing conditions are given in Table 1 . All the three process parameters have three levels. The designed experiments are shown in Table 2. Each column represents a process parameter, whereas a row stands for processing condition, which is nothing but a combination of parameter levels. The flexural test was carried out on these experiments and replicated three times. In this work three different kinds of process variables are selected which are mostly affecting the processing condition. General thermoplastic composites significantly get affected by the process temperature, time of curing, and mould pressure. By running initial pilot study to understand the closest possible range of those process parameters in any experimental condition assumption of closed process parameters is very essential before commencing the experiment. In this BoxBehnken experiment 15 runs are executed with 3 replications for minimizing the standard error. This Box-Behnken design minimizes the cost of experimentation significantly.

These experiments were conducted based on Box-Behnken second order design for three variables. Experimental design was used to investigate the effects of the process parameters like mould temperature $\left(X_{1}\right)$, mould pressure $\left(X_{2}\right)$, and holding time $\left(X_{3}\right)$ on the flexural strength of the glass yarn reinforced polypropylene thermoplastic composites. These variables were selected at fixed three levels, $-1,0$, and +1 . 
TABLE 3: Three-factor Box-Behnken design experiment with predicted response of dependent variable (flexural strength in Mpa).

\begin{tabular}{|c|c|c|c|c|c|c|c|}
\hline \multirow{3}{*}{ Runs } & \multicolumn{6}{|c|}{ Factors } & \multirow{3}{*}{$\begin{array}{c}\text { Response } \\
\text { Flexural strength in Mpa }\end{array}$} \\
\hline & \multicolumn{3}{|c|}{ Coded } & \multicolumn{3}{|c|}{ Actual } & \\
\hline & $\mathrm{X} 1$ & $\mathrm{X} 2$ & $\mathrm{X} 3$ & $\mathrm{X} 1$ & $\mathrm{X} 2$ & $\mathrm{X} 3$ & \\
\hline 1 & 0 & 0 & 0 & 15 & 220 & 3 & 55.58 \\
\hline 2 & -1 & -1 & 0 & 10 & 200 & 3 & 60.33 \\
\hline 3 & 1 & -1 & 0 & 20 & 200 & 3 & 56.6 \\
\hline 4 & -1 & 0 & 1 & 10 & 220 & 4 & 89.34 \\
\hline 5 & 0 & 0 & 0 & 15 & 220 & 3 & 55.58 \\
\hline 6 & 0 & 0 & 0 & 15 & 220 & 3 & 55.58 \\
\hline 7 & 0 & 1 & -1 & 15 & 240 & 2 & 45.52 \\
\hline 8 & 0 & -1 & -1 & 15 & 200 & 2 & 69.4 \\
\hline 9 & -1 & 1 & 0 & 10 & 240 & 3 & 65.42 \\
\hline 10 & 1 & 1 & 0 & 20 & 240 & 3 & 42.03 \\
\hline 11 & -1 & 0 & -1 & 10 & 220 & 2 & 79.43 \\
\hline 12 & 0 & -1 & 1 & 15 & 200 & 4 & 55.03 \\
\hline 13 & 1 & 0 & -1 & 20 & 220 & 2 & 65.38 \\
\hline 14 & 1 & 0 & 1 & 20 & 220 & 4 & 79.66 \\
\hline 15 & 0 & 1 & 1 & 15 & 240 & 4 & 57.7 \\
\hline
\end{tabular}

The response $(Y)$ is given by a second order polynomial as shown below:

$$
Y=b_{0}+\sum_{i=1}^{K} b_{i} X_{i}+\sum_{i=1}^{k} b_{i i} X_{i}^{2}+\sum_{i>j}^{k} \sum_{i=1}^{k} b_{i j} X_{i} X_{j},
$$

where $Y$ is predicted response, $X_{1}, X_{2}$, and $X_{3}$ are independent variables, $b_{0}$ is offset term, $b_{1}, b_{2}$, and $b_{3}$ are linear effects, and $b_{11}, b_{22}$, and $b_{13}$ are interaction terms.

\section{Results and Discussions}

This section discusses the experimental findings using the main effect of the process parameters on response and interaction effects, contour analysis, and analysis of variance (ANOVA) to estimate the effect of parameter on flexural strength of the Glass/PP based thermoplastic composites. Based on the contour analysis optimal combination of process parameters has found. Furthermore, the variation of mechanical properties of thermoplastic composites with process parameters is modelled mathematically using the multiple linear regression analysis method.

5.1. Analysis of Variance. The model $F$ value of 11.72 implies the model is significant. There is only a $0.72 \%$ chance that a "model $F$ value" this large could occur due to noise. Values of "prob. > F" less than 0.0500 indicate model terms are significant. In this case $X_{1}, X_{2} X_{3}, X_{1}^{2}, X_{2}^{2}$, and $X_{3}^{2}$ are significant model terms. The terms $X_{2} X_{3}, X_{1}^{2}, X_{2}^{2}$, and $X_{3}^{2}$ indicate that interaction effect between mould temperature and holding time was significant and the quadratic effects of mould pressure and holding time were also significant.

5.2. Regression Analysis. The results obtained from the 15 experimental runs carried out according to the Box-Behnken design are summarised in Table 3 . The proposed second
TABLE 4: ANOVA for response surface quadratic model of flexural strength.

\begin{tabular}{lccccc}
\hline Source & Sum of squares & Df & Mean square & $F$ value & $\begin{array}{c}P \text { value } \\
\text { prob. }>F\end{array}$ \\
\hline Model & 2228.03 & 9 & 247.56 & 11.72 & 0.0072 \\
X1-pressure & 323.22 & 1 & 323.22 & 15.30 & 0.0113 \\
X2-temp. & 117.73 & 1 & 117.73 & 5.57 & 0.0647 \\
X3-time & 60.50 & 1 & 60.50 & 2.86 & 0.1514 \\
X1X2 & 96.63 & 1 & 96.63 & 4.57 & 0.0855 \\
X1X3 & 4.77 & 1 & 4.77 & 0.23 & 0.6545 \\
X2X3 & 176.23 & 1 & 176.23 & 8.34 & 0.0343 \\
X1 ${ }^{2}$ & 449.01 & 1 & 449.01 & 21.25 & 0.0058 \\
X2 & 408.05 & 1 & 408.05 & 19.32 & 0.0071 \\
X3 $^{2}$ & 518.05 & 1 & 518.05 & 24.52 & 0.0043 \\
Residual & 105.62 & 5 & 24.52 & & \\
Lack of fit & 105.62 & 3 & 21.12 & & \\
Pure error & 0.000 & 2 & 35.21 & & \\
Cor. total & 2333.65 & 14 & 0.000 & & \\
\hline
\end{tabular}

degree polynomial was fitted to the data presented in Table 4 using multiple linear regressions to determine the optimum fermentation conditions that resulted in the maximum flexural strength (Mpa). The effects of mould pressure, mould temperature, and holding time on flexural properties of the thermoplastic composites were quantitatively evaluated using response surface curves. By applying multiple regression analysis on the experimental data, the following second degree polynomial was

$$
\begin{aligned}
Y= & 55.58-6.36 X_{1}-3.84 X_{2}+2.75 X_{3}-4.91 X_{1} X_{2} \\
& +1.09 X_{1} X_{3}+6.64 X_{2} X_{3}+11.03 X_{1}^{2} \\
& -10.51 X_{2}^{2}+11.84 X_{3}^{2} .
\end{aligned}
$$




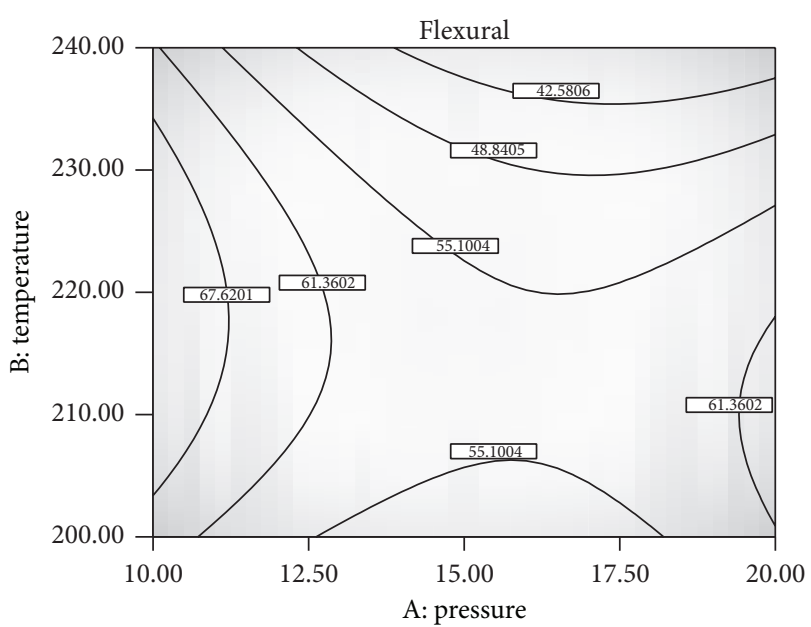

Design-expert software Flexural

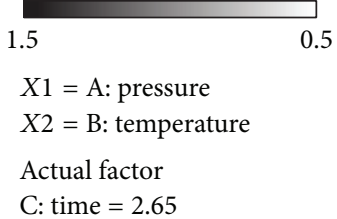

FIGURE 2: Contour between mould pressure and mould temperature keeping holding time as constant.

The coefficient of determination $\left(R^{2}\right)$ of the model was 0.9547 which indicated that the model adequately represented the real relationship between the variables under consideration. An $R^{2}$ value of 0.9547 means that $95.4 \%$ of the variability was explained by the model.

5.3. Optimization of Flexural Strength of the Composite. In order to optimise the variables that influence the flexural strength of the thermoplastic composite material, the response surface plots were generated from the regression model. The three-dimensional (3D) plots were generated by keeping one variable constant at the centre point and varying the others within the experimental range. The resulting response surfaces showed the effect of mould temperature, mould pressure, and holding time on flexural strength of the composite material.

Figures 2 to 4 represent the response surface and contour plots for the optimization of flexural property. Figure 2 shows the response surface and corresponding contour plots for flexural strength as a function of mould pressure and mould temperature. An increase in the temperature with an accompanying decrease in moulding pressure resulted in an increase in flexural strength (Mpa) from about $42 \mathrm{Mpa}$ to a maximum value of $67.72 \mathrm{Mpa}$ at $11 \mathrm{bar}$ pressure and $220^{\circ} \mathrm{C}$.

The effect of mould pressure and holding time on the flexural strength of the composite is presented in Figure 3. The trend observed that an increase in holding time with an accompanying decrease in mould pressure yields increase in flexural strength of the composite from $65.1 \mathrm{Mpa}$ to a maximum of 81.1 at 11 bar pressure and 3.5 min holding time.

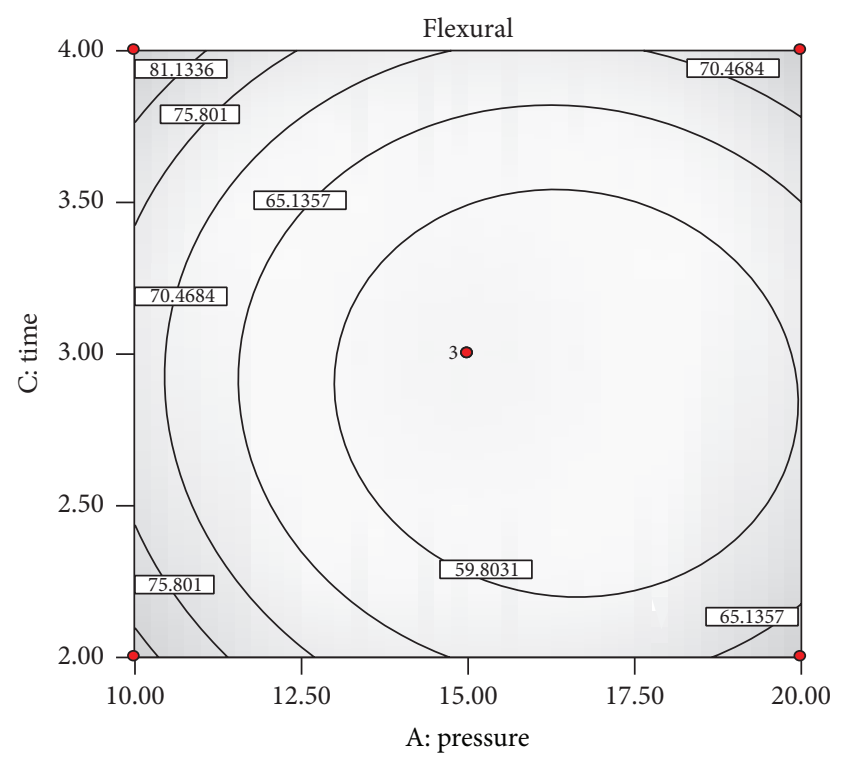

Design-expert software

Flexural

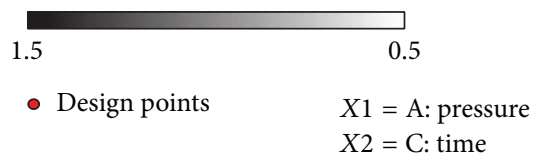

Actual factor

B: temperature $=220.00$

FIGURE 3: Contour between mould pressure and holding time keeping mould temperature as constant.

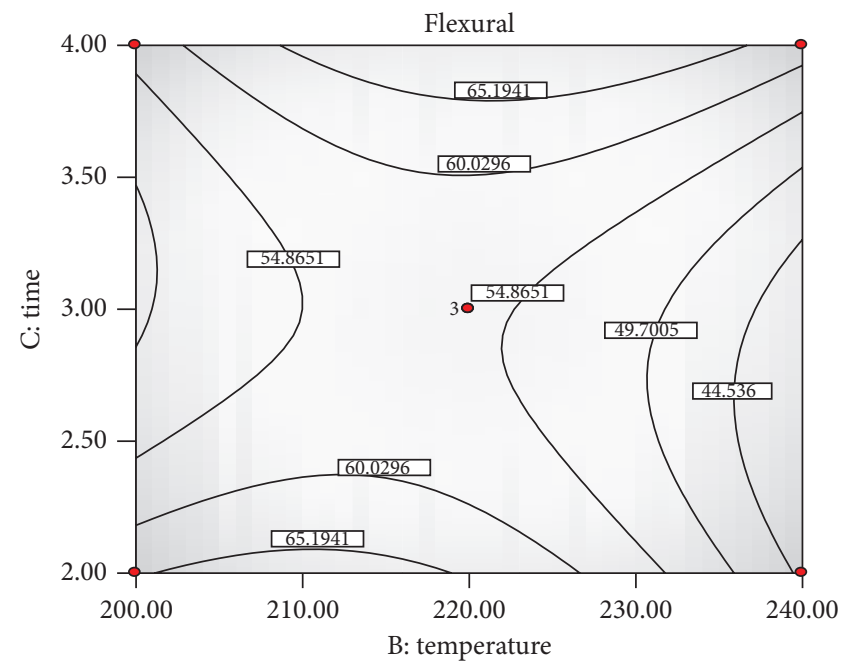

Design-expert software

Flexural

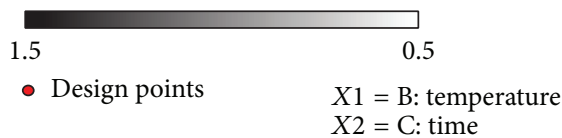

Actual factor

A: pressure $=15.00$

FIGURE 4: Contour between mould temperature and holding time keeping mould temperature as constant. 
Figure 4 indicates the interaction effect between the process parameters such as of mould temperature and holding time. The trend observed indicated that high value of flexural strength was predicted for different combination of low mould temperature and low holding time as well as low temperature and high holding time. The best flexural strength is obtained in 220 mould pressure and 3.5 holding time.

In order to select the optimum conditions and their respective levels, the model was analysed. The maximum response of flexural strength of the composite was predicted at $81.13 \mathrm{Mpa}$. The final optimised process parameters through magnified contour analysis are obtained as 11.1 bar mould pressure, $3.09 \mathrm{~min}$ holding temperature, and $220^{\circ} \mathrm{C}$ mould temperature. In general, the polypropylene fibre has low melting temperature; when the temperature exceeds more thermal degradation occurs. This obviously leads to a nonreversible reduction of fiber strength. Since this polypropylene is the matrix component this thermal degradation affects the mechanical properties of the composite.

\section{Conclusion}

The effects of hot press forming process parameters on flexural properties of Glass/PP wrapped fibre composites are experimentally investigated. As the experimental results show, stamp forming processing temperature, mould pressure, and holding time have most significant effect on flexural properties of the composite material. study.

The following other conclusions can be drawn from the

(i) The use of response surface methodology the researcher found the optimum region in the selected process parameters (mould pressure, mould temperature and press holding time) for obtaining the maximum flexural strength of the composite material.

(ii) Flexural strength is highly influenced by these process parameters; quadratic effects of some of the parameters and interaction effects of mould temperature and holding time were established.

(iii) The quadratic regression model was formed with the inclusion of the mentioned process.

(iv) The combination of process parameters were a flexural strength is maximum at were 11.1 bar mould pressure, $3.09 \mathrm{~min}$ holding time, and $220^{\circ} \mathrm{C}$ mould temperature.

\section{Conflict of Interests}

The authors declare that there is no conflict of interests regarding the publication of this paper.

\section{References}

[1] J. A. M. Ferreira, J. D. M. Costa, and M.O.W. Richardson, "Effect of notch and test conditions on the fatigue of a glass-fibrereinforced locating the acoustic emission," Polymer Composites, vol. 5, pp. 329-339, 1993.
[2] M. Hou, L. Ye, and Y.-W. Mai, "Manufacturing of an aileron rib with advanced thermoplastic composites," Journal of Thermoplastic Composite Materials, vol. 10, no. 2, pp. 185-195, 1997.

[3] Fink, "Advanced themoplastic material composites," Polymer Engineering \& Science, vol. 30, 1990.

[4] F. P. La Mantia and M. Morreale, "Green composites: a brief review," Composites A, vol. 42, no. 6, pp. 579-588, 2011.

[5] S. Shinichi, Y. Cao, and I. Fukumoto, "Flexural modulus of the unidirectional and random composites made from biodegradable resin and bamboo and kenaf fibres," Composites A, vol. 39, no. 4, pp. 640-646, 2008.

[6] K. Oksman, M. Skrifvars, and J.-F. Selin, "Natural fibres as reinforcement in polylactic acid (PLA) composites," Composites Science and Technology, vol. 63, no. 9, pp. 1317-1324, 2003.

[7] A. Maurizio, G. Bogoeva-Gaceva, A. Buzuarovska, M. E. Errico, G. Gentile, and A. Grozdanov, "Poly (3-hydroxybutyrate-co3-hydroxyvalerate)-based biocomposites reinforced with kenaf fibers," Journal of Applied Polymer Science, vol. 104, no. 5, pp. 3192-3200, 2007.

[8] P. A. Sreekumar, P. S. Thomas, J. M. Saiter, G. Unnikrishnan, and S. Thomas, "Viscoelastic and thermal properties of eco-friendly composites fabricated by resin transfer molding," Journal of Reinforced Plastics and Composites, vol. 30, no. 17, pp. 1509-1516, 2011.

[9] A. M. Ferreira, Fink, and J. D. M. Costa, "Study the angle of lay on the mechanical properties of thermo plastic materials," Polyner Composites, vol. 7, p. 52, 1995.

[10] H. Ku, H. Wang, N. Pattarachaiyakoop, and M. Trada, "A review on the tensile properties of natural fiber reinforced polymer composites," Composites B, vol. 42, no. 4, pp. 856-873, 2011.

[11] S. Ochi, "Mechanical properties of kenaf fibers and kenaf/PLA composites," Mechanics of Materials, vol. 40, no. 4-5, pp. 446452, 2008.

[12] M. Bernard, A. Khalina, A. Ali et al., "The effect of processing parameters on the mechanical properties of kenaf fibre plastic composite," Materials and Design, vol. 32, no. 2, pp. 1039-1043, 2011.

[13] H. Takagi and A. Asano, "Effects of processing conditions on flexural properties of cellulose nanofiber reinforced "green" composites," Composites A, vol. 39, no. 4, pp. 685-689, 2008.

[14] S. Rassmann, R. G. Reid, and R. Paskaramoorthy, "Effects of processing conditions on the mechanical and water absorption properties of resin transfer moulded kenaf fibre reinforced polyester composite laminates," Composites A, vol. 41, no. 11, pp. 1612-1619, 2010.

[15] M. Rezaei, N. G. Ebrahimi, and A. Shirzad, "Study on mechanical properties of UHMWPE/PET composites using robust design," Iranian Polymer Journal, vol. 15, no. 1, pp. 3-12, 2006.

[16] N. A. Amenaghawon, K. I. Nwaru, F. A. Aisien, S. E. Ogbeide, and C. O. Okieimen, "Application of box-behnken design for the optimization of citric acid production from corn starch using Aspergillus niger," British Biotechnology Journal, vol. 3, no. 3, pp. 236-224, 2013. 

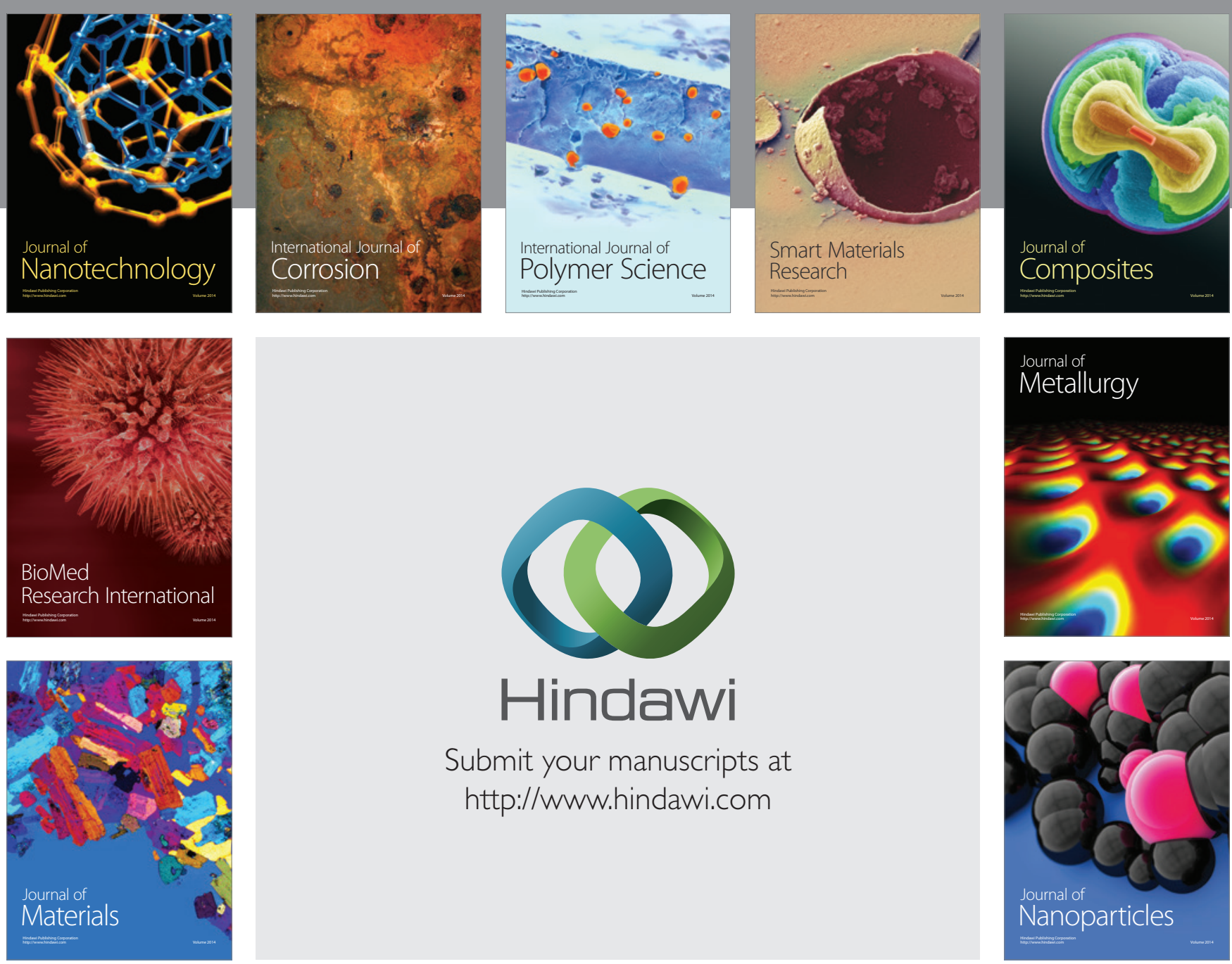

Submit your manuscripts at http://www.hindawi.com
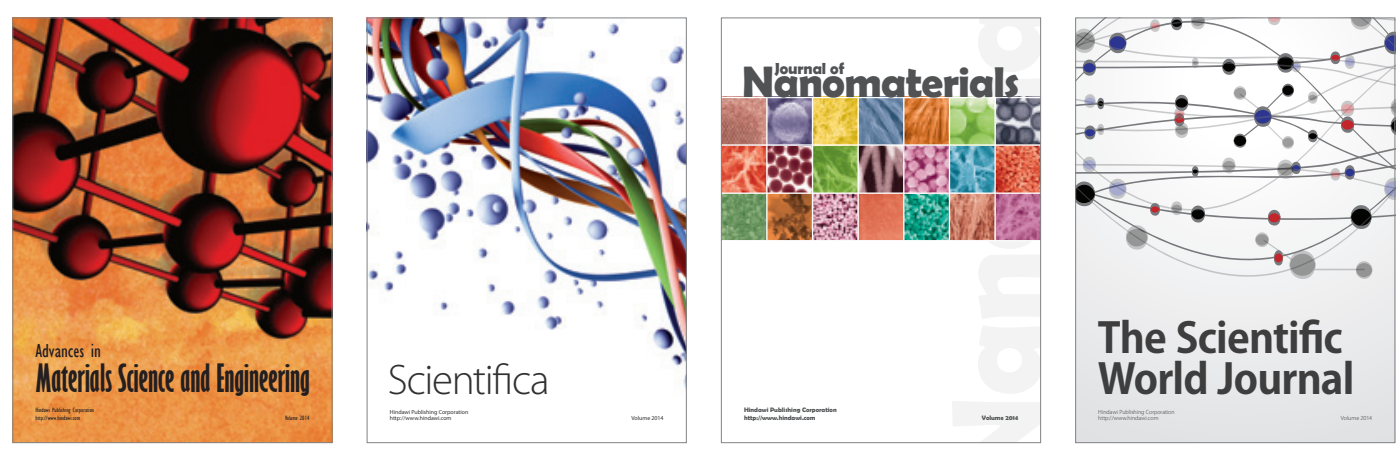

\section{The Scientific World Journal}
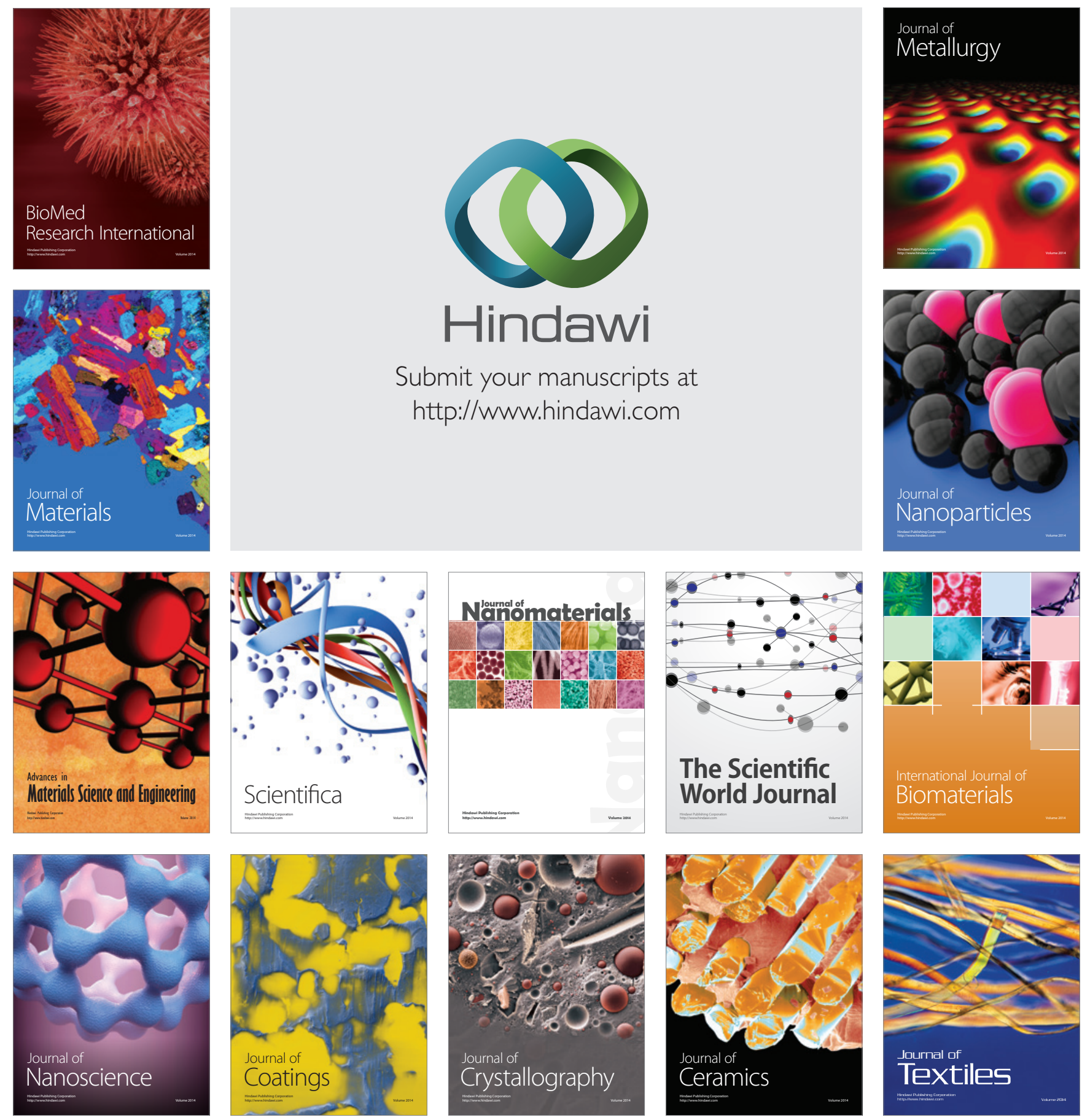